\title{
Load kick-back effects due to activation of demand response in view of distribution grid operation.
}

Han, Xue; Sossan, Fabrizio; Bindner, Henrik W.; You, Shi; Hansen, Henrik; Cajar, Peder Dybdal

Published in:

Proceedings of 5th IEEE PES Innovative Smart Grid Technologies

Link to article, DOI:

10.1109/ISGTEurope.2014.7028976

Publication date:

2014

Link back to DTU Orbit

Citation (APA):

Han, X., Sossan, F., Bindner, H. W., You, S., Hansen, H., \& Cajar, P. D. (2014). Load kick-back effects due to activation of demand response in view of distribution grid operation. In Proceedings of 5th IEEE PES Innovative Smart Grid Technologies IEEE. https://doi.org/10.1109/ISGTEurope.2014.7028976

\section{General rights}

Copyright and moral rights for the publications made accessible in the public portal are retained by the authors and/or other copyright owners and it is a condition of accessing publications that users recognise and abide by the legal requirements associated with these rights.

- Users may download and print one copy of any publication from the public portal for the purpose of private study or research.

- You may not further distribute the material or use it for any profit-making activity or commercial gain

- You may freely distribute the URL identifying the publication in the public portal 


\title{
Load kick-back effects due to activation of demand response in view of distribution grid operation
}

\author{
Xue Han*, Fabrizio Sossan*, Henrik W. Bindner*, Shi You*, Henrik Hansen ${ }^{\dagger}$, and Peder D. Cajar ${ }^{\ddagger}$ \\ ${ }^{*}$ CEE, Technical University of Denmark, Email: xueh, hwbi, sy, faso@elektro.dtu.dk \\ ${ }^{\dagger}$ Danish Energy Association, Email: heh@danskenergi.dk \\ ${ }^{\ddagger}$ DONG Energy A/S, Email: pedca@dongenergy.dk
}

\begin{abstract}
There are increasing potentials to utilize the flexibilities from demand side resource (DSR) units. They can provide grid operation services by shifting or curtailing their energy consumption. The service provision can be achieved by aggregating a large quantity of DSR units in the network. The paper has shown how aggregated consumption dynamics introduce new peaks in the system due to the synchronous behaviors of a portfolio of homogeneous DSRs, which is instructed by the flexibility management system. This dynamic effect is recognized as load kick-back effect. The impact of load kick-back effects onto the distribution grid is analysed in this paper by establishing scenarios based on the estimation of DSR penetration levels from the system operator. The results indicate some risks that the activation of demand response may create critical peaks in the local grid due to kick-back effects.
\end{abstract}

Index Terms-flexibility, demand side resource, distribution grid operation, load kick-back effect, demand response

\section{INTRODUCTION}

Large quantities of intermittent renewable energy sources, and decentralized power generations are anticipated to play important roles in the future European energy system [1]. We are also experiencing the fact that some conventional centralized power plants are shut down due to less energy production and high maintenance cost. To maintain the power system operation and to balance the production and consumption, demand side resource (DSR) existing in the system is an attractive candidate to provide ancillary services, to balance the power, and thus to postpone or cancel the grid reinforcement.

DSRs are small units installed at the end-users in distribution grid that have the ability to adjust their consumption as requested, such as electrified space heating and cooling systems, configurable white goods (e.g., washing machine), and electric vehicles (EVs). Many articles have investigated various services that DSRs can provide to the power system [2]-[5]. The services are achieved by shifting or curtailing the power consumption (i.e., flexibility) of individual units, without violating their primal functionality (e.g., keeping indoor temperature for a space heating system). Individual flexibilities from DSRs of a large population are aggregated to upscale the size to affect the grid operation. This fact leads to various operating constraints and limitations of DSRs. As the flexible consumption portions from DSRs cannot be simply regarded as a fully controllable virtual unit, the DSR management systems are confronted with some obstacles on planning and allocating the usage of flexibility.
Load kick-back effect, a.k.a, "cold load pick-up (CLPU)", is originally studied given the circumstances that load may exceed the level at any time before the outage during the system restoration [6]. It is because all individual behaviors are temporarily synchronized due to the disturbance of power supply. [7] introduced the model to describe the dynamics of water heaters during CLPU. This phenomenon may also occur when demand response is being activated: the DSRs will be instructed to behave identically to fulfill both the service request and their operating constraints (see Fig. 1). Kick-back effects are also observed in some studies [3]-[5], [8]. In [4], the EV fleet is instructed to charge when price is low. The new charging schedule introduced several peaks in a day. The authors in [3] give a power reference to a portfolio of water heaters. The total consumption follows the reference, but the individual temperatures move away from their initial values at the end of the simulation period, which leads to a potential kick-back. But not so many studies are aware of and comprehend the potential load kick-back effects when they commit the services through DSR aggregation.

The dynamics of the aggregated DSR response when activating services should be investigated, given the high potential of demand response and utilization of DSR flexibility in the future distribution grid operation. In [9], the aggregated dynamic response of a large homogeneous population of DSR units is studied. It shows how an identical control signal introduces dynamics of the aggregated response, and individual behaviors in different point in time. In this paper, the impact of load kickback effect onto the grid will be further evaluated through Monte Carlo simulations of a portfolio of DSR units. It is shown that an identical control signal to all the DSR units without being aware of the kick-back effects may result in new congestion issues in the network. It also gives a quantitative comparison of the original vital conditions and new ones due to kick-back effect.

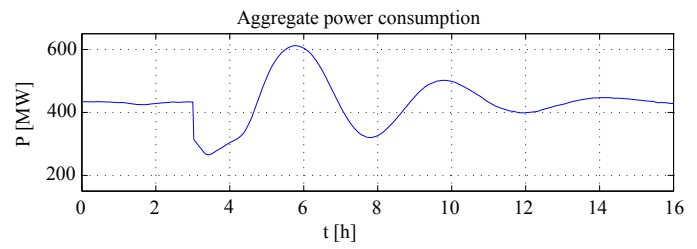

Fig. 1: Load kick-back due to demand flexibility [9]. 
The remainder of the paper is structured as follows. Section II describes the DSR dynamic models, their responsive control algorithm, and the aggregated control setup. Section III presents grid model, load model, and the allocation of DSR units. It is followed by section IV, containing simulation results and analyses by investigating different operating criteria. The paper is concluded in section V.

\section{DSR POPULATION AND THEIR CONTROL STRATEGY}

A remote control setup is considered for aggregating the DSRs and providing system services as shown in Fig. 2. An artificial price curve (Fig. 3) is used as an incentive signal to instruct the DSR performance in real-time. The responsive controllers of the individual DSRs convert the control signal to their control inputs via their own personalized strategy. It is assumed that the price is not affected by demand response. Two types of homogeneous DSR populations are considered in the setup: house heating system and EVs. The amount of DSR units, in our case, EVs and space heating systems are determined by their estimated penetrations.

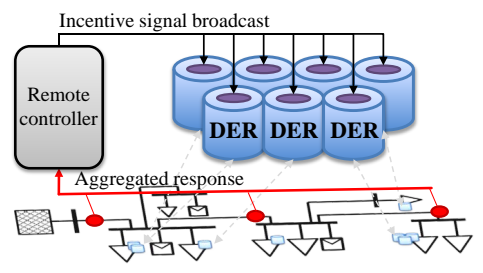

(a) Remote control loop

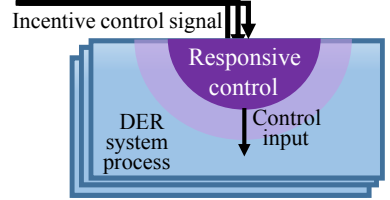

(b) local DSR responsive controller
Fig. 2: Sketch diagram of control setup.

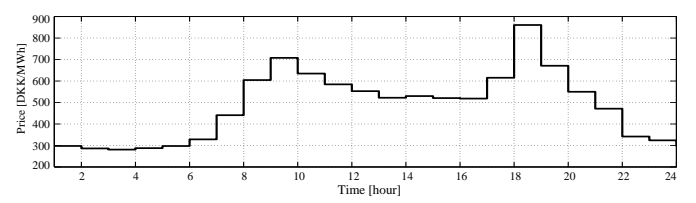

Fig. 3: Illustration of the incentive signal.

In the personalized responsive strategy, a threshold price is used to reflect the customer willingness to adapt the energy consumption to the incentive signal. Hence, it is determined by the thresholds whether a DSR shifts its consumption with respect to the control inputs:

$$
o_{\text {grid }, j, t}= \begin{cases}0 & \text { if the price is higher than the threshold, } \\ 1 & \text { elsewise. }\end{cases}
$$

The threshold values of the population follow a normal distribution as illustrated in Fig. 4.

\section{A. DSR models}

1) Space heating system: The space heating system model consists of two parts: heat pump (thermostatic controlled), and the associated house (the energy buffer) as shown in Fig. 5. In this paper, $o_{\text {grid }, j, t}$ is the control input deployed in the

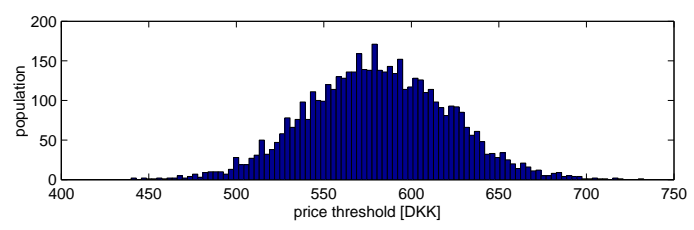

Fig. 4: Stochastic realization of price threshold values.

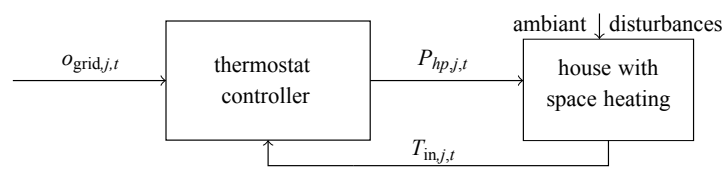

Fig. 5: Heat pump model diagram.

setup. Other control input options are the temperature setpoint, operational power rate, etc.

The heat pump circulates a refrigerant and transmit the energy from one volume to another in a closed loop. Coefficient of performance (COP) indicates how efficient the heat pump uses electric power to heat the house, which varies from 4.4 to 4.7 depending on the indoor and outdoor temperatures. The size of heat pump $P_{h p}^{\text {rate }}$ is defined as $3 \mathrm{~kW}$. The start-up consumption spike is defined as $1 \mathrm{~kW}$ lasting 10 minutes. Each building of the population is equipped with a thermostat which controls the indoor temperature according a set-point $T_{\text {ref }}\left[{ }^{\circ} \mathrm{C}\right]$ set as $22^{\circ} \mathrm{C}$. The threshold of the thermostat controller is $\pm 1^{\circ} \mathrm{C}$ and it is assumed the same for all the buildings.

A first order house model is used to represent the primary usage of the heat pump, i.e., keeping the indoor temperature as agreed with the owner. The value of indoor temperature $T_{\text {in }}$ $\left[{ }^{\circ} \mathrm{C}\right]$ represents the amount of energy stored in the house. It is affected by the outdoor temperature $T_{\text {out }}\left[{ }^{\circ} \mathrm{C}\right]$ due to the house insulation, and the heating energy input from the heat pump system $P_{h p}[\mathrm{~kW}]$ that compensates the thermal loss. The discretized expression of the model using $t$ as the sample time of building $j$ is expressed as

$$
T_{\mathrm{in}, j}(t+1)=A_{j} T_{\mathrm{in}, j}(t)+B_{0, j} P_{h p, j}+B_{1, j} T_{\mathrm{out}, j} .
$$

where, $A_{j}, B_{0, j}$, and $B_{1, j}$ are thermal parameters to form the thermostatic model. Their values are related to the building characteristics. The corresponding data can be found in [9].

The thermostatic control algorithm is defined as

$$
P_{h p, j}=\frac{P_{h p}^{\text {rate }}}{C O P} o_{\text {grid }, t} o_{\text {state }, t},
$$

where, $o_{\text {state }, t}$ is the binary thermostatic operating state:

$$
o_{\text {state }, t}= \begin{cases}0 & T_{\mathrm{in}, j} \geq T_{\mathrm{in}}^{\max } \\ 1 & T_{\mathrm{in}, j} \leq T_{\mathrm{in}}^{\min } \\ o_{\text {state }, t-1} & \text { elsewise. }\end{cases}
$$

2) Electric vehicle charging: EVs are modelled as portable batteries, of which the availability (i.e., in this study, available when parking at home) and the daily battery consumption are determined by owners' driving patterns. "Vehicle to grid" 
concept is not considered in our study (i.e., no bi-directional power flow). The EV charging and consuming (to convert chemical energy to mechanical energy) rate are simplified as defined power value regardless battery states. The maximal charging rate $P_{e v}^{\max }$ is $3.7 \mathrm{~kW}$. The charging efficiency $\eta_{1}$ is approximated as 0.9 , the consumption efficiency $\eta_{2}$ is approximated as 0.87 , and the energy use $\operatorname{conv}_{e}$ is approximated as $32.5 \mathrm{kWh} / 160 \mathrm{~km}[10]$. The driving patterns are approached by randomly selecting driving records of vehicles in Denmark during workdays in a database [11].

Three parameters are used to capture the patterns: time arriving at home, time leaving home, and daily driving distance. The daily driving distance is limited within $160 \mathrm{~km}$. Short athome period (i.e., less than 1 hour) are ignored in the record. By having the above-mentioned properties, the behaviours of electric vehicles are captured in the model. EV $i$ 's charging is modelled by the following equations (also see Fig. 6):

$$
\begin{aligned}
& P_{i, t}^{e 2 m}=\frac{1}{\eta_{2}} D_{i, t} \operatorname{conv}_{e} / \Delta T, \\
& P_{i, t}^{c h}=O_{i, t} \eta_{1} P_{e v, i, t}, 0 \leq P_{e v, i, t} \leq P_{e v}^{\max }, \\
& E_{i, t+1}^{\mathrm{d}}=E_{i, t}^{\mathrm{d}}+\left(P_{i, t}^{c h}-P_{i, t}^{e 2 m}\right) \Delta T, E_{i, t_{\text {leave }}}^{\mathrm{d}}=0 .
\end{aligned}
$$

where, $P_{i, t}^{e 2 m}[\mathrm{~kW}]$ is the consumed electric power of EV $i$ at time $t$, which depends on the driving distance $D_{i, t}$ $[\mathrm{km}] ; P_{i, t}^{c h}[\mathrm{~kW}]$ is the converted chemical power; the daily battery consumption $E_{i, 0}^{\mathrm{d}}[\mathrm{kWh}]$ is determined by customer behaviours and it should be compensated before EV leaving home, as indicated by $E_{i, t_{\text {leave }}}^{\mathrm{d}} . P_{e v, i, t}[\mathrm{~kW}]$ is the electric charging consumption; $\Delta T$ is the sampling time in [h]. The indicator for charging is $O_{i, t}$.

The charging logic is implemented as:

$$
\begin{aligned}
& O_{i, t}=o_{\text {full }} \cdot o_{\text {home }} \cdot o_{\text {order }}, \\
& o_{\text {order }}=1-\left(1-o_{\text {grid }}\right)\left(1-o_{\text {owner }}\right) .
\end{aligned}
$$

where, $o_{\text {full }}$ indicate whether the battery is full, $o_{\text {home }}$ indicate whether the vehicle is at home, and $o_{\text {order }}$ indicate whether it is allowed to charge. $o_{\text {order }}$ is 'true' when either the the controller allows through $o_{\text {grid }}$ or the owner must charge EV through $o_{\text {owner }}$. $O_{\text {owner }}$ is determined by comparing the energy to be charged $E_{\mathrm{d}, i, t}$ and the maximal charging capacity $\eta_{1}$. $P_{\text {ev }, i, t} \cdot\left(t_{\text {leave }}-t\right) / \Delta T$.

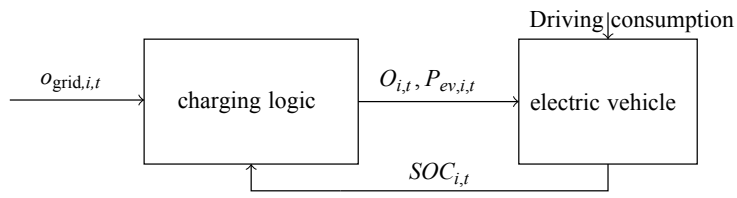

Fig. 6: Electric vehicle model diagram.

\section{STUDY CASE DESCRIPTION}

\section{A. Grid model}

A real Danish medium-voltage (MV) feeder B02 at $10 \mathrm{kV}$ is used for the simulations (see Fig. 7). It is a radial feeder, which connects to other feeders with normally opened breakers. Each

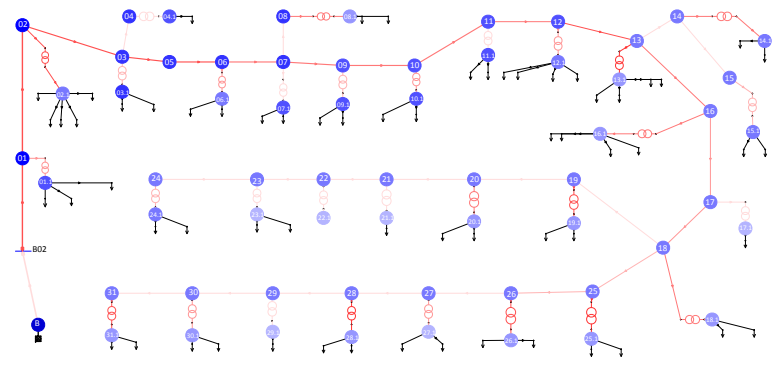

Fig. 7: A Danish MV feeder.

node along the feeder is associated with a secondary substation and lumped loads. The grid model is built in NEPLAN [12], which can receive the load profiles as inputs for load flow calculations. Feeder B02 contains 31 nodes, including 26 small customer groups and 14 large customers. The nodes are connected with each other through 31 underground cables. The sizes of cables vary from one to another depending on the estimation of load flow given future scenarios.

\section{B. Load model}

Under each secondary substation transformer, the portions of different load categories are specified. The lumped load profile is determined by the estimated annual consumption and corresponding templates of each load categories in each week of a year. Annual consumption of existing load is estimated by the base consumption and its yearly increase. Considering the condition in Denmark that most of heat pumps operate in winter, we use the load profiles and temperature conditions in week 50 for the following simulations.

Location and population of DSR units are associated with certain types of loads. EVs are anticipated to be connected to the residential houses and buildings, while the potential locations of heat pump systems are electric-heated houses. The population is also related to the penetration estimate [13] [14]. The penetration levels and the corresponding numbers of DSRs in the MV feeder are listed in Table I.

TABLE I: Penetration level of EVs and heat pumps.

\begin{tabular}{c|cc|cc}
\hline \multirow{2}{*}{ Year } & \multicolumn{2}{|c|}{ Heat pump } & \multicolumn{2}{c}{ Electric vehicle } \\
\cline { 2 - 5 } & Quantity & Penetration & Quantity & Penetration \\
\hline \hline 2013 & 0 & $\sim 0 \%$ & 0 & $0 \%$ \\
\hline 2020 & 75 & $3 \%$ & 122 & $8 \%$ \\
\hline 2030 & 365 & $10 \%$ & 242 & $20 \%$ \\
\hline
\end{tabular}

\section{Simulation Results}

Three essential operation constraints are chosen to measure the grid operation performance:

- Node voltage: according to EU Standard EN50160 [15], the variation of voltage magnitude 10-minute average rms value should be within $\pm 10 \%$ of the nominal value for $95 \%$ of time ${ }^{1}$. Considering the fact that MV distribution

\footnotetext{
${ }^{1}$ The LV grid areas are modelled as lumped loads in the grid model. Hence, the voltage drop in LV grid areas will not be considered in our study
} 
area and LV area share the range of $\pm 10 \%$, and a suboptimal position of fixed tap-changer at secondary substation, $\pm 5 \%$ is set as an indicator of critical voltage deviation situation in our study.

- Line loading: according to the "N-1" criterion, $30 \%$ of the cable capacity is reserved for emergency operation. Two measuring points are set: $70 \%$ loading is the indicator of heavy loading condition, and $100 \%$ loading is the hard limit of overloading. The capacity of lines (cables) are defined in current [Amp].

- Transformer loading: similar to line loading, 70\% loading and $100 \%$ loading are the two measuring points for transformer loading conditions. The capacity of transformers are defined in apparent power [kVA].

Based on the models mentioned before, Monte Carlo simulations are used to estimate the average performance of the portfolio of DSR units in the MV feeder. The detailed description stochastic terms of space heating systems and EVs can be found in [9] and [11].

\section{A. Loading of $M V / L V$ transformers}

The most loaded secondary substation is selected to illustrate the results (see Fig. 8). The grey and light pink curves are the load profiles of 2000 simulations by random selecting the load patterns of EVs and the house thermostatic model parameters of the space heating systems. The dash-dot lines are the profiles by taking the average of 2000 simulations. The solid lines in figure are the original profiles calculated based on the aggregated load model at secondary substation without counting the installed DSR units.

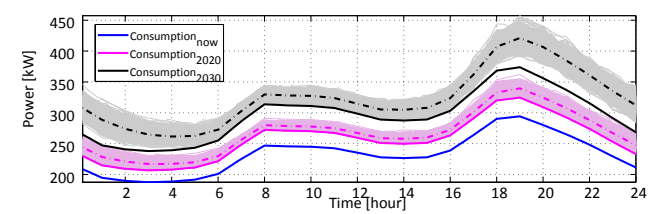

(a) without control

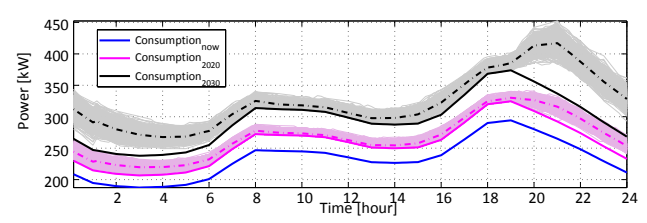

(b) with control

Fig. 8: The load profiles with (dash-dot lines)/ without (solid lines) EVs and heat pumps in different years.

It can be seen that part of the load is shifted from 17:00 19:00 to later at night. $O_{\text {grid }, i}$ signal turns 1 after the original peak hour. More under-controlled DSRs start consume power than in the steady state after the controlling period. Their consumption is added onto the existing uncontrollable load, which introduces a new peak. Comparing to the ordinary cases without control, it is seen that more power is consumed from 12:00 to $16: 00$ and less is consumed from 8:00 to 10:00.
But around the evening peak, the kick-back power comes too fast so that the peak is generated on the base load in 21:00 (mainly due of EV charging). In addition, the peak is more severe in 2030 case due to larger penetration of EVs. There is not much difference on the peak values but only on the time when they occur. The kick-back does not occur sharply. It is mainly because that personalized response is introduced, and it diversifies the customer behaviours. This phenomenon inspires that the stochastic or diversified terms may flatten the kickback peak. The loading of all the transformers along time in a merit order is shown in Fig. 9 by taking the average of all 2000 simulations. It is noticeable that the original peak is reduced to less than $80 \%$ loading and less cables are overloaded, but a new peak is generated afterwards. The maximal loading in the network is reduced to approximately $80 \%$ of the capacity.

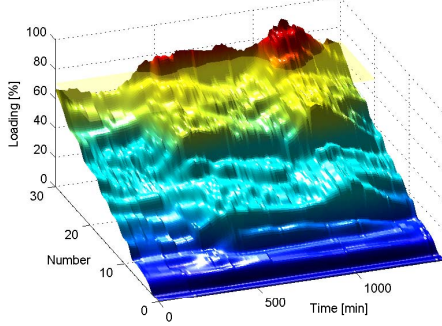

(a) without control

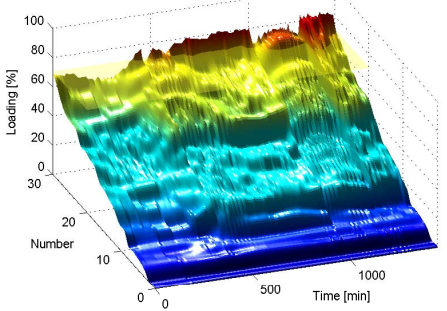

(b) with control
Fig. 9: Loading of transformers in 2030 scenario in merit order along time.(The yellow transparent surface indicate $70 \%$ loading. The colors of surfaces indicate the loading value.)

\section{B. Loading of lines}

Similar results can be drawn for line loading. The kick-back peaks are more severe and visible in 2030 cases. The merit ordered loading curves for all lines are plotted in Fig. 10. There are large blue areas in all plots, which indicate more than 10 lines are over-sized and thus have low values for the whole day. Some of them is due to the backup interconnection with other feeders when the topology changes. Other lines are more of interest. From the plots we can see that there is very little difference of curves for all lines at original and new peak time. There are almost the same amount of cables are heavily loaded with and without controlling the flexibility during new and original peak hours. However, it is noticeable that the DSR management keeps the loading below $70 \%$ of the capacity for longer time (i.e., morning peak is removed). Take the line L_B02_01_1 (the most loaded line) in 2030 case as an example. There is $80 \%$ of the day when the loading is below $70 \%$ capacity with control, whereas there is only $63 \%$ of the day without applying any control applications (see Fig. 11). The size of shifted flexibilities has some impacts on the size of the kick-back load. Some room for accommodating the kick-back should be reserved when activating the flexibility services to avoid new critical conditions. 


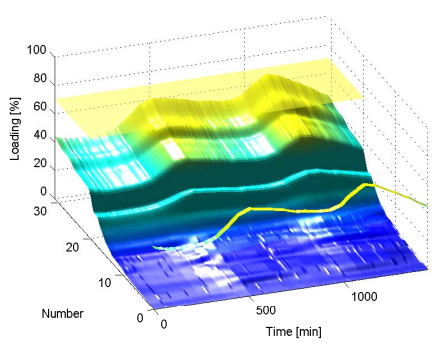

(a) 2020 without control

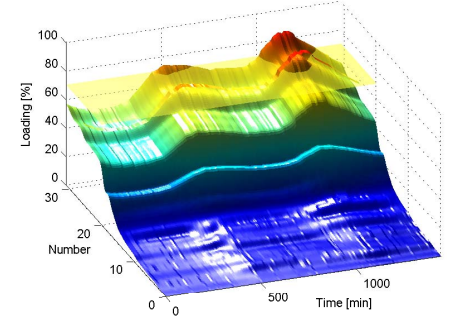

(c) 2030 without control

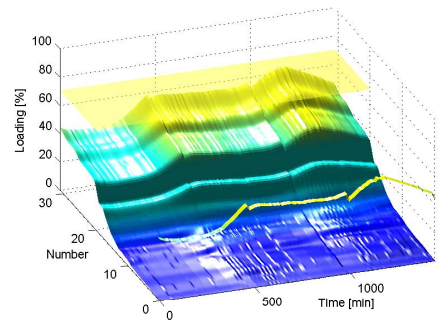

(b) 2020 with control

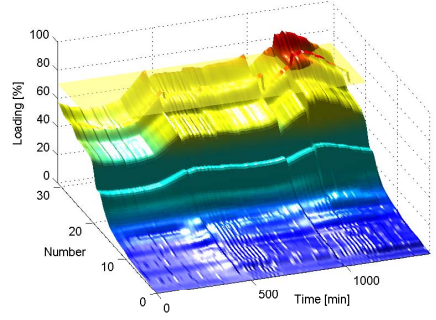

(d) 2030 with control

Fig. 10: Line loading in merit order along time.(The yellow transparent surface indicate $70 \%$ loading. The colors of surfaces indicate the loading value. The band indicates the profile of L_B02_01_1.)
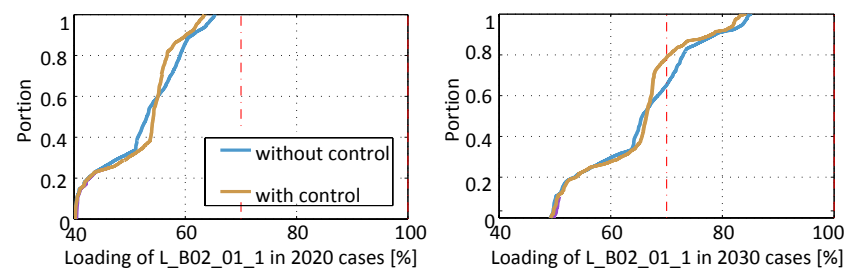

Fig. 11: CDF curves of line loading of L_B02_01_1.

\section{Voltage profile}

To obtain a better feeder voltage profile, the voltage at the primary substation is set to $10.4 \mathrm{kV}$. In the cases without distributed generation, voltage drops from the head to the end. The most severe node in terms of voltage is the node that is most distant from the primary substation. Daily voltage profiles of the last node B02.31 in the feeder are plotted in Fig. 12. The drop at original peak time is brought back due to the activation of flexibility. There is mismatch between high price and local peak and critical voltage condition, so the price is no longer higher than the threshold value when the local peak occurs. More and more DSRs resume their consumption when the local voltage is still low. The voltage goes down again due to the kick-back effect. Therefore, the lowest voltage magnitude is not improved so much when the flexibility control is applied. The same conclusion can be drawn from Fig. 13. The dark blue area in Fig. 13 is reduced and shifted from 18:00 - 19:00 to 19:00 - 20:00 range. From the results, it can be highlighted that if the load kickback effects can be reduced by improving the control strategy, there is large potential to bring lowest voltage magnitudes up. However, it is difficult with lack of knowledge on the local

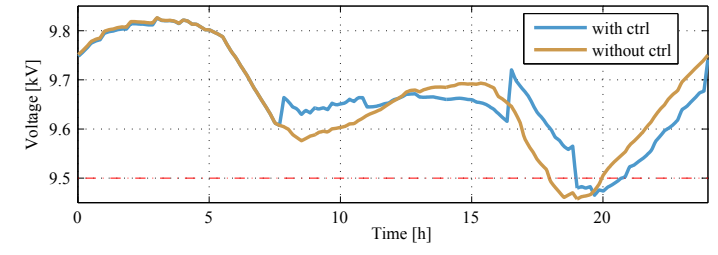

Fig. 12: Daily voltage profiles in 2030 cases at the last node in the feeder (at MV side of secondary substation).

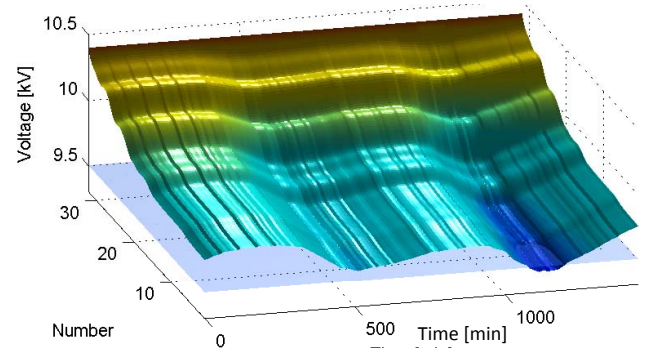

(a) without control

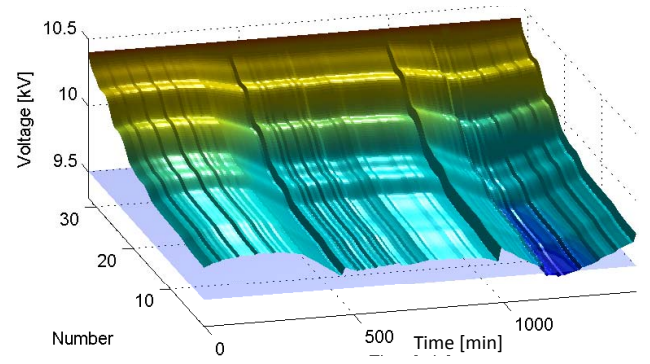

(b) with control

Fig. 13: Voltage profile in 2030 cases in merit order along time.(The blue transparent surface indicate $9.5 \mathrm{kV}$ level. The colors of surfaces indicate the voltage.)

constraints while designing the control strategies.

\section{Analysis}

Table II sums the results of scenario 2020 and 2030. It shows the most critical value of individual criteria in the test feeder and the most critical time instant. It also summarized the number of lines that are heavily loaded ( $>70 \%$ loading), the number of transformers that are heavily loaded $(>70 \%$ loading), and the number of nodes of which the voltage is below $95 \%$.

By observing the results corresponding to the aforementioned three operating criteria, it can be seen that the price signals reflect the global system operation states, while the local grid states and constraints are not entirely considered or acknowledged in the control frame. When the flexibility services are provided, it may happen that the optimality is not always achieved in the local grid area. The load kick-back effect after the load shifting may create new critical operating conditions. A sharper load increase could occur if the customer responses are more harmonized (e.g., when the price is very high). In the simulations, we can see that in 2030 case, the new peak is almost equal to the original one. 
TABLE II: Summary of the most critical moments and the corresponding state values.

\begin{tabular}{|c|c|c|c|c|c|c|c|c|c|c|c|c|}
\hline \multirow{2}{*}{ Year } & \multirow{2}{*}{ Ctrl } & \multicolumn{2}{|c|}{ Peak load $[\mathrm{kW}]$} & \multicolumn{2}{|c|}{ Voltage drop [kV] } & \multicolumn{2}{|c|}{ Line loading [\%] } & \multicolumn{2}{|c|}{ Tr. loading [\%] } & \multirow{2}{*}{$\begin{array}{l}\text { No. of } \\
\text { nodes }\end{array}$} & \multirow{2}{*}{$\begin{array}{c}\text { No. of } \\
\text { Tr.s }\end{array}$} & \multirow{2}{*}{$\begin{array}{l}\text { No. of } \\
\text { lines }\end{array}$} \\
\hline & & size & time & size & time & size & time & size & time & & & \\
\hline 2013 & - & 275.6 & $18: 30$ & 9.67 & $18: 30$ & 54.31 & $18: 30$ & 61.84 & $18: 30$ & 0 & 0 & 0 \\
\hline 2020 & No & 339.5 & $18: 30$ & 9.57 & $18: 30$ & 65.24 & $18: 30$ & 74.14 & $18: 30$ & 0 & 1 & 0 \\
\hline 2020 & Yes & 330.0 & $19: 40$ & 9.59 & $19: 10$ & 63.56 & $19: 40$ & 73.75 & $19: 40$ & 0 & 1 & 0 \\
\hline 2030 & No & 421.4 & 19:00 & 9.45 & 19:00 & 85.2 & $19: 00$ & 91.33 & 19:00 & 7 & 7 & 6 \\
\hline 2030 & Yes & 417.6 & 19:40 & 9.47 & 19:40 & 81.42 & $19: 40$ & 91.95 & 20:00 & 5 & 7 & 6 \\
\hline
\end{tabular}

\section{CONCLUSION AND FUTURE WORK}

Demand side DSRs and their flexibility provide an alternative way to assist system operations, e.g., power balancing, and congestion management. The services requested by the remote entity instruct DSR units to perform same or similar actions to their flexibility. The harmonized actions of a large quantity of homogeneous DSRs would generate kick-back effects. The kick-back load might increase the network load.

A Danish MV distribution grid has been presented to analyse the power system operation and to assess the risks by activating the flexibility services. Space heating systems and EVs, as two typical types of DSRs, are modelled to provide flexibility services. An incentive signal is used to instruct the load shifting performances. By analyzing the transformer loading at secondary substations, the line loading along the feeder, and the voltage profile, we have identified that load kick-back effects may create new critical conditions in the local grid and power imbalance.

In this paper, the focus is oriented to the impacts on the grid. From the analysis of the results, we can conclude that load kick-back effects have some negative impacts on the grid operation in terms of generating new critical load conditions, worsening voltage quality, overloading grid components, and thus creating new contingency conditions in the operation. With higher penetration of DSR units in the grid, more flexibility can be expected from this grid area. Kick-back effect is generated due to the temporary synchronization of DSR behaviours in the dynamic state of the entire population. Larger kick-back load may eventually be produced by activating more available flexible resources, which may not distributed following the grid conditions. If the kick-back peak is larger than the original peak, there is a risk that flexibility services may endanger the grid operation and damaging the grid properties.

The incentive signal used in the simulations is system wide and thus does not take local constraints into consideration, which is another cause of critical situations. Some local problems might be ignored and consequently enlarged after activating the flexibility services. If the load kick-back effects can be reduced or handled by improving the control strategy, the flexibilities existed locally can contribute more on the local grid operation as well as providing services to higher grid level. The employment of flexibilities should also respect the local grid conditions. For instance, the local controller should reserve some flexibility to be adjusted according to the local measurement. It requires that the local constraints and operation states are acknowledged and respected when designing the control strategy and during the control process. There are several ways to release or to mitigate the critical loads by managing the effects when designing the flexibility services and remote control algorithms. The feedback loop containing the DSR states is important to estimate and predict the future dynamics. Subsequently, the DSR aggregate model is important to obtain an accurate prediction. The local desynchronizing factors, e.g., diversified responsive strategies, or some random parameters in the process controller can damp the harmonized dynamics rather fast. The local grid operating constraints should be communicated with the flexibility provider, so that they are visible in the control and aggregation strategy. These factors to mitigate the load kick-back effects will be further analyzed in our study.

\section{REFERENCES}

[1] T. Kapetanovic, K. Takac, and M. S. Jimenez, "Task force for smart grids expert group 3: Roles and responsibilities of actors involved in the smart grids deployment,' EU Commission, Tech. Rep., Apr. 2011.

[2] F. Sossan, A. M. Kosek, S. Martinenas, M. Marinelli, and H. Bindner, "Scheduling of domestic water heater power demand for maximizing pv self-consumption using model predictive control," in Innovative Smart Grid Technologies Europe (ISGT EUROPE), 2013 4th IEEE/PES. IEEE, 2013, pp. 1-5.

[3] S. Koch, "Demand response methods for ancillary services and renewable energy integration in electric power systems," Ph.D. dissertation, Power Systems Laboratory, ETH Zurich, 2012.

[4] O. Sundstrom and C. Binding, "Planning electric-drive vehicle charging under constrained grid conditions," in Power System Technology (POWERCON), 2010 International Conference on. IEEE, 2010, pp. 1-6.

[5] P. Pinson, T. Jnsson, and H. Madsen, "Indirect control by prices - basic concepts, applications and requirements," iPower Project Work Package 4, Tech. Rep., Jul. 2012.

[6] D. Miller and T. Sleva, "Cold load pickup issues," Power System Relay Committee of The IEEE Power Engineering Society, Tech. Rep., May 2008.

[7] S. Lee and C. Wilkins, "A practical approach to appliance load control analysis: a water heater case study," power apparatus and systems, ieee transactions on, no. 4, pp. 1007-1013, 1983.

[8] F. Sossan and H. Bindner, "A comparison of algorithms for controlling dsrs in a control by price context using hardware-in-the-loop simulation," in PES General Meeting, 2012 IEEE. IEEE, 2012, pp. 1-6.

[9] F. Sossan, X. Han, and H. Bindner, "Dynamic behaviour of a population of controlled-by-price demand side resources," in Proceedings of the IEEE Power Energy System General Meeting, 2014. IEEE, accepted for publication.

[10] A. H. Foosnæ s, "EDISON WP1.1 electric vehicle technology," EDISON Consortium, Tech. Rep., 2010, http://www.edison-net.dk/Dissemination/ Reports.

[11] S. You, J. Hu, and A. B. Pedersen, "Numerical comparison of optimal charging schemes for electric vehicles," in Power and Energy Society General Meeting, 2012 IEEE. IEEE, 2012, pp. 1-6.

[12] NEPLAN. (2014). [Online]. Available: www.neplan.ch

[13] Energinet.dk. (2014). [Online]. Available: http://www.energinet.dk/

[14] DONG Energy. (2014). [Online]. Available: http://www.dongenergy.dk/

[15] "Voltage Characteristics in Public Distribution Systems," EN standard 50160 . 